\title{
Entre poesis y scientia: aspectos del alfabeto poético de la naturaleza en Antonio Machado y Eugenio Montale
}

\author{
Cristiana FIMIANI \\ Universidad de Granada \\ cfimiani@ugr.es
}

\begin{abstract}
RESUMEN
Esta investigación surge a raíz de la existencia de prometedoras y aún no examinadas afinidades entre las detalladas nociones paisajísticas de Antonio Machado y la vasta erudición geobotánica de Eugenio Montale, quien conocía y admiraba la obra del poeta andaluz gracias a la lectura de la Antología de Gerardo Diego. El artículo sigue un enfoque comparatista entre las literaturas de dos lenguas "hermanas" y halla su inspiración en el sugerente interrogante retórico que plantea el maestro sevillano: "Naturaleza es sólo un alfabeto / de la lengua poética. / Pero ¿hay otro mejor?".

El autor de Campos de Castilla menciona una extraordinaria cantidad de plantas, espontáneas o cultivadas, con el rigor científico de un experto naturalista, y comparte su "simple amor a la Naturaleza" (y amor a lo simple de la naturaleza) con el autor de Ossi di seppia; la "poesia delle cose" del genovés, sobre cuya selección de ejemplares vegetales se intuye la inconfundible huella machadiana, se orienta hacia esos ásperos y rocosos paisajes de su Liguria natal que le desvelan valores cósmicos. Ambos poetas comparten la misma mirada pormenorizada del hic et nunc, análogas estrategias descriptivas, un stilus miserorum y la descripción de paysages de l'âme neo-simbolistas.
\end{abstract}

Palabras clave: Simbolismo botánico, paysage de l'âme, A. Machado y E. Montale, Literatura vs. Ciencias Naturales

\begin{abstract}
This investigation arises in the wake of the existence of promising and not yet examined affinities between Antonio Machado's detailed notions about landscape and Eugenio Montale's wide geo-botanical knowledge; he knew and admired Andalusian poet's work thanks to the reading of Gerardo Diego's Anthology. The article follows a comparative perspective between the literatures of two "sister" languages and finds its inspiration in the suggestive rhetorical question asked by the Sevillian author: "Nature is only an alphabet / of the poetic language / But, is there a better one?".

The author of Campos de Castilla mentions an extraordinary quantity of wild or cultivated plants with the scientific exactitude of an expert naturalist and shares his "simply love of
\end{abstract}


Nature" (and love towards the simplicity of Nature) with the author of Ossi di seppia; the "poetry of objects" by the Genovese poet, whose selection of vegetables specimens intuits Machado's clear mark, is oriented towards those rough and rocky landscapes of his native Ligury region that reveal him cosmic values. Both poets share the same detailed look of hic et nunc, analogous descriptive strategies, a stilus miserorum and the description of neosimbolic paysages de l'âme.

Keywords: Botanical symbolism, paysage de l'âme, A. Machado and E. Montale, Literature vs. Natural Sciences

Captada por la retina y luego filtrada a través de la esfera emocional, la vegetación se convierte en paisaje gracias a la proyección de la imaginación del sujeto lírico (también, por un juego especular, del lector activo), que la recrea tanto según los códigos culturales y los cánones estéticos e ideológicos de la época como según sus sentimientos y estados de ánimo coyunturales. Por lo tanto, si la percepción del entorno natural no puede ser nunca íntegramente "objetiva", aún menos consigue serlo en los versos de Antonio Machado (1875-1939), un poeta que "se ve a sí mismo, se siente a sí mismo en el paisaje. O se le extiende el paisaje por los espacios infinitos de su alma" 1 .

Se ha comprobado que dicha constante paisajística ${ }^{2}$ aparece asimismo en Eugenio Montale (1896-1981), ambos autores enmarcados en la dialéctica -de claro corte postromántico- entre simbolismo y existencialismo (la doble cara inmanencia/trascendencia de sus "correlatos objetivos" botánicos) y, además, en la sugerente fase de transición de la estética modernista a la vanguardia. ${ }^{3}$

${ }^{1}$ B. Mostaza (1949), p. 641.

${ }^{2}$ A la hora de examinar los temas más recurrentes en la obra machadiana, los planteamientos críticos de mayor impacto han hecho hincapié en conceptos metafísicos tales como la angustia existencial, el miedo a la muerte y la constante búsqueda de Dios "entre la niebla", la simbología de sueños y recuerdos, la metáfora del "camino" como iter ontológico y esencial a través de las "galerías" del alma; nuestro viaje exploratorio por los paisajes -tanto andaluces como castellanos- de su poesía ha ido desvelando, en cambio, el protagonismo absoluto atribuido al ámbito espacial antes que al temporal. Esta clave de lectura resulta confirmada por Dámaso Alonso, quien apunta acertadamente que "lo primero que vemos es espacio: algo se abre y se profundiza ante nosotros. Siempre en su poesía hay un espacio que se abre y se ilumina". D. Alonso (1962), p. 168.

${ }^{3}$ Los dos tienden a encarnar instintivamente en una determinada imagen de la naturaleza (un paisaje o un detalle de su vegetación) las características peculiares de una impresión que haya despertado en ellos una resonancia profunda, para anclarlas a una realidad que aparezca más sólida y objetiva. El marco externo de la vegetación -que actúa como límite espacial ante el fluir de las emociones- se va transfigurando, sin embargo, según los parámetros subjetivos del 
Este trabajo, que forma parte de un proyecto más amplio de minuciosa individuación y sistemática catalogación de todas las especies botánicas mencionadas en el corpus lírico machadiano y montaliano ${ }^{4}$, nace al hilo de la constatación del vacío crítico existente en torno a un tema tan sugerente como se perfila el de una "herborización" que resulte -dentro de los límites permitidos por el campo poético- lo más exhaustiva posible.

De la escasez de estudios críticos sobre esta área temática liminal -en la que poesis y scientia se encuentran y dialogan de forma constructiva- ya parecía consciente Giovanni Pascoli; el poeta romañolo, indiscutible precursor de las alusiones naturales (específicamente florales) en el marco de la moderna tradición literaria italiana, se quejaba -en Il fanciullino (El muchachito) de 1897- de que "el pueblo italiano" no diese la importancia debida a cosas tales como "flores, plantas, pájaros, insectos, reptiles, que componen en gran parte la poesía del campo [...]"5.

Hay que tener en cuenta además que la perspectiva innovadora de un cruce fructífero entre el ámbito de las ciencias naturales y humanísticas contribuye a arrojar luz tanto sobre la exégesis textual y las coyunturas sociohistóricas (dos guerras mundiales y fascismo en el caso de Montale, guerra civil española y la primera Gran Guerra en el de Machado) como sobre la evolución de las distintas corrientes líricas en el primer tercio del siglo XX.

Los poemas "mal vestidos" de don Antonio -que son ejemplo de sobriedad y honestidad sin máscaras ni exuberancias- esconden, debajo de un atuendo humilde, la riqueza de una significación densa y auténtica ${ }^{6}$, y desvelan una original cultura en el campo de las Ciencias Naturales (especialmente en el de la geobotánica), reflejada en su mirada constantemente orientada a los detalles más desapercibidos de la

observador y enriqueciendo de valores simbólicos y/o de connotaciones específicas que generalmente adquieren sentido solo en relación a unos estados de ánimo personales.

${ }^{4}$ El plan de trabajo del proyecto definitivo cuenta también con un análisis filológico/etimológico de los términos con que Machado y Montale designan las varias especies (y sub-especies) arbóreas y florales, con el fin de averiguar la efectiva precisión lexical de dichas menciones vegetales y su correcta ubicación en el marco paisajístico descrito, en virtud de la asimilación de nociones de botánica debida al contacto directo con el paisaje y/o a su erudición bibliófila.

${ }^{5}$ La traducción del fragmento extrapolado es nuestra. A continuación transcribimos la versión original del texto italiano: "Se il popolo italiano badasse a queste tali cose, fiori, piante, uccelli, insetti, rettili, che formano per gran parte la poesia della campagna, il nome che esse hanno in una terra, avrebbe finito per prevalere su quello dominante in altre. Ma gl'italiani abbarbagliati per lo più dallo sfolgorio dell'elmo di Scipio, non sogliono seguire i tremolii cangianti delle libellule". R. La Valva (1999), p. 56.

${ }^{6}$ Es lo que puntualiza Rafael Alberti al precisar que "esa modestia, esa humildad de medios, esa diaria escasez, son su inmensa riqueza, el tesoro que nos ha dejado y que cada día que pasa logra una nueva altura y mayor resplandor". R. Alberti (1945), p. 46. 
vegetación. Valga como ejemplo la perspectiva "democratizadora" con la cual Machado describe los encinares de la "augusta sierra" del Guadarrama en la composición titulada "Las encinas", donde pone de relieve, con una potente anáfora, justamente las características menos llamativas de esta especie de "cenicienta" arbórea, tales como su follaje oscuro y sus flores nada vistosas que, por no desprender un olor agradable ni destacar cromáticamente, no suelen llamar la atención de pintores y poetas:

En tu copa ancha y redonda nada brilla, ni tu verdioscura fronda ni tu flor verdiamarilla. ${ }^{7}$

Dicho interés peculiar, que supera en él -según declaración del propio autor- "infinitamente" al del Arte, resulta heredado de su entorno familiar (el abuelo paterno fue el primer catedrático de Geología en España y profesor de Historia Natural en Sevilla y Madrid) y asimismo desarrollado gracias a la educación liberal-progresista adquirida en la Institución Libre de Enseñanza.

Montale, que recibió el Premio Nobel de Literatura en 1975, declara que "diez versos de Antonio Machado nos bastan para percibir la presencia de la gran poesía" ${ }^{\prime}$, y orienta sus versos crípticos hacia los elementos florales y faunísticos más insignificantes de las Cinco Tierras ligures de su infancia, tales como la célebre imagen de esos "huesos de sepia" que inspirarán el título de su poemario de 1925; sin embargo, estos "nimios" le revelarán los valores cósmicos de un paisaje que, según la definición del propio autor, se perfila como "universal", puesto que llega a abarcar toda la poliédrica morfología del mundo vegetal por medio de una compleja variedad lingüística tanto específica como más genérica. ${ }^{9}$

La correspondencia con la perspectiva paisajística machadiana se revela patente: en la primera de las nueve partes de "Campos de Soria", el sujeto lírico dirige su atención al análisis de la conformación del terreno (ya en sí misma poéticamente

${ }^{7}$ A. Machado (1989), CIII, vv. 66-69, p. 502.

${ }^{8}$ E. Montale (1996), p. 1904.

${ }^{9}$ El especial enfoque natural del genovés, que literalmente da la espalda a lo "sublime" de los paisajes majestuosos, se refleja en la significativa anécdota biográfica que transmite Francisco Ferrer: "El poeta genovés Montale fue llevado por un amigo lombardo a visitar cierto grandioso paraje alpino. El fondo del valle se cerraba por un bloque de hielo, las fuerzas poderosas de la Naturaleza habían horadado aquel titánico muro, y, a través de un orificio perfectamente circular, brillaba el azul radiante del cielo. Montale, desatando la indignación de sus anfitriones, no prestó al soberbio espectáculo la más mínima atención. Como cegado por la luz, dio la espalda al valle e inició el regreso”. E. Montale (1973), p. 9. 
atípica) y a la descripción de la orografía numantina; luego se detiene a contemplar, dentro de una vasta gama de especies botánicas, algunos de los más irrelevantes ejemplares de la flora castellana: las hierbas aromáticas y las primeras margaritas que bordan los prados primaverales. Resulta sorprendente observar que, según un original "trastrueque de planos por el que lo secundario, los elementos que habitualmente se integran en el telón de fondo de una obra artística, pasan a ocupar o compartir el lugar principal"10, el solemne Moncayo (con sus laderas aún nevadas a comienzos de abril) se queda lejos de la mirada del lector-espectador, relegado a un segundo plano, ya que Machado le dedica tan solo un verso:

Es la tierra de Soria árida y fría.

Por las colinas y las sierras calvas, verdes pradillos, cerros cenicientos, la primavera pasa dejando entre las hierbas olorosas sus diminutas margaritas blancas. La tierra no revive, el campo sueña. Al empezar abril está nevada la espalda del Moncayo ${ }^{11}$

El ex-estudiante de la Institución, que consideraba los paseos al aire libre por los campos y las montañas más formativos que cualquier otra actividad deportiva, demuestra conocer perfectamente tanto la morfología y composición del terreno como su relativa biocenosis. Tras las huellas de su maestro Giner de los Ríos, que veía en el contacto con el paisaje una oportunidad única para estimular "el ennoblecimiento de las emociones, la dilatación del horizonte intelectual, la dignidad de nuestros gustos y el amor a las cosas morales" ${ }^{, 2}$, su alumno llegará a sugerir la necesidad de "despertar en el niño el amor a la naturaleza, que se deleita en contemplarla, o la curiosidad por ella, que se empeña en observarla y conocerla"13, para luego poder individuar su más imperceptible detalle geológico y arbóreo.

Con la misma mirada escrutadora, Montale, que se propone "torcer el cuello" a la "vieja lengua áulica" 14 de la tradición, observa un paisaje que se puebla de plantas y animales, en los que la vida queda reducida a formas mínimas o que revelan tan solo leves estelas de su pasado. Este planteamiento llevará a la famosa definición de la "poesía de las cosas" que, forjada con cuadros de paisajes esenciales, se

${ }^{10}$ R. Vila-Belda (2004), p. 123.

${ }^{11}$ A. Machado (1989), CXIII, vv. 1-9, pp. 511-512.

${ }^{12}$ F. Giner de los Ríos (1915), p. 361.

13 A. Machado (1973), p. 52.

${ }^{14}$ La traducción es nuestra. E. Montale (1976), p. 656. 
puebla de presencias concretas y habituales y con aquellos "árboles sagrados" erguidos (como dramatis personae) contra el humano "male di vivere". Paradigmática encarnación de su poética serán precisamente las plantas "asimiladas a la vida, a la renovación, a la fecundidad" ", árboles frutales como aquellos limoneros que, emblema de una realidad desnuda y áspera, pero intensamente viva y coloreada, inspirarán el título de uno de sus poemas más conocidos.

La sintonía con Machado depende en buena parte precisamente de este rechazo de la versificación sublime de la lírica oficial a favor de una poesía de objetos comunes: cabe señalar la declaración de ars poetica que, al comienzo de su carrera literaria, el hermético inmortaliza en los versos de "I limoni", donde se perciben los ecos inconfundibles del limonero machadiano, el cítrico que el sevillano elige como símbolo privilegiado de la aetas aurea de la infancia ${ }^{16}$ :

Escúchame, los poetas laureados se mueven solamente entre las plantas de nombres poco usados: bojes ligustres o acantos.

Yo prefiero los caminos que desembocan en los herbazales, zanjas donde en charcos medio secos agarran los muchachos alguna extenuada anguila: los senderos que siguen los ribazos, descienden entre los penachos de las cañas y penetran en los huertos, entre los árboles de los limones. ${ }^{17}$

Montale se decanta aquí por el empleo de un stilus miserorum y, paladín de la polémica de los "crepuscolari" y de la "Ronda" contra el esteticismo dannunziano, se opone a la mención de plantas ornamentales como los "bojes", los "ligustres" o los "acantos" (presentes desde la lírica renacentista, barroca y arcádica, hasta los poemas de Giosuè Carducci y Gabriele D'Annunzio); y asimismo rechaza las flores típicas de los "poetas laureados" -es decir, los escritores consagrados por la tradición, con referencia irónica a la costumbre antigua de coronarlos con hojas de laurel (símbolo máximo de la gloria lírica) - tales como el lirio o la rosa.

${ }^{15}$ C. López Cortezo (1982), p. 146.

${ }^{16}$ Machado suele colocar el limonero, frutal característico de los jardines andaluces, dentro de un marco que se podría definir como el locus amoenus por excelencia de su lírica, cerca de aquella fuente que simboliza, en su fluir eterno, el panta rhei del tiempo; de un tiempo que no podrá cicatrizar las heridas más dolorosas ni disipar las dudas que angustian al poeta, quien se dirigirá hacia los elementos de la Naturaleza para buscar en ellos consuelo y respuestas eficaces, en un diálogo que se perfila como un monólogo desdoblado consigo mismo.

17 E. Montale (1973), vv. 1-10, p. 19. 
Como se señalaba antes, también Machado, en lugar de cantar las especies arbóreas más llamativas, legendarias o exóticas, prefiere dedicar todo un poema al árbol más "intrahistórico" del bosque mediterráneo:

La historia botánica de España la hacen los árboles fuertes y altos, los hermosos, los grandes y los olorosos -el roble, el pino, la palmera, el chopo, el manzano, el eucalipto, el naranjo-. La protagonista de la intrahistoria botánica, que en este largo poema también se cuenta, es la pobre "encina campesina". ${ }^{18}$

Aquella "parda encina", que generalmente no provoca admiración ni respeto, es elegida como alegoría del pueblo castellano y símbolo privilegiado del campo en el que crece: "El campo mismo se hizo / árbol en ti, parda encina" (CIII, vv. 78-79, p. 502).

Ningún artista ha pintado su sobria belleza y la dignidad de su porte, que no tiene nada del orgullo fiero y guerrero de los demás árboles, como certeramente observa Carlos Beceiro:

En oposición a otros árboles, el roble señorial y guerrero, el pino de múltiples paisajes, la palmera de los confines del desierto, las hayas de temible leyenda, los chopos temblorosos en la orilla del río, las añosas olmedas, el manzano, el eucalipto o el naranjo, con su aroma, o el ciprés con su elegancia, la encina se evidencia por caracteres de signo negativo. Ni color, no olor, ni prestancia... ${ }^{19}$

A sus flores discretas -Machado volverá a recordarlo en la séptima de las "Canciones" de CLIX- nadie dirige su mirada, aunque embellezcan unas ramas destinadas a morir heroicamente, sin oponer resistencia, bajo los golpes crueles del hacha de los leñadores:

Canta de la parda encina la rama que el hacha corta y la flor que nadie mira. ${ }^{20}$

El poeta deja claro, sin embargo, que también la humildad con que la encina extiende sus ramas desteñidas desde el tronco polvoriento, sin arrogancia y sin sufrimiento, esconde, en realidad, una personalidad vigorosa y decidida:

¿Qué tienes tú, negra encina campesina, con tus ramas sin color

${ }^{18}$ A. Barbagallo (1990), p. 33.

${ }^{19}$ C. Beceiro (1984), p. 50.

${ }^{20}$ A. Machado (1989), CLIX (VII), vv. 4-6, p. 621. 
en el campo sin verdor;

con tu tronco ceniciento

sin esbeltez ni altiveza,

con tu vigor sin tormento,

$\mathrm{y}$ tu humildad que es firmeza? ${ }^{21}$

Machado llora el funesto destino de estos árboles que se inmolan estoicamente para ofrecer calor a los campesinos, sin que nadie les dedique un canto in memoriam:

Mientras que llenándoos va

el hacha de calvijares,

¿nadie cantaros sabrá, encinares? ${ }^{22}$

Símbolo de esa fuerza que puede proceder solo de una actitud firme y de una humildad innata, las vigorosas representantes del Quercus ilex, que crecen prevalentemente en los ásperos y pedregosos lugares montanos, cubren las laderas del Pardo; el monte madrileño debe su nombre precisamente al color verde oscuro de las hojas de los "encinares castellanos" que inspiraron el poema dedicado a los señores Masriera, profesores de dibujo de la Institución Libre de Enseñanza, en recuerdo de una excursión entre aquellos paisajes sublimes.

Más allá de todo cambio meteorológico, del calor tórrido de agosto al hielo invernal de enero, de las gotas del aguacero a los copos de nieve de la tormenta, se yergue -"siempre firme, siempre igual"- la "eterna encina rural", que encara valiente e impasible las distintas pruebas a las que la existencia la somete. Machado

${ }^{21}$ Ibíd., CIII, vv. 58-65, p. 502. Es el carácter valiente de la gente del campo, de esos "buenos aldeanos" de los que las "encinas campesinas" se perfilan como "la sombra tutelar", y a los que proporcionan la leña para sus humildes hogares: "Especie de lazarillo de los árboles, sometida al medio mineral, manteniendo su vida en precario frente al adverso terruño, la encina es un símbolo del sufrido pueblo español, parco, humilde y estoico, a vueltas con la vida y el sustento, en la rudeza de una tierra estéril; firme y resistente en su pobreza. Como el campesino, también la encina se confunde con la parda paramera; soporta lluvias y fríos, se expande por llanos y cerros y, aunque solicitada a veces por el arte palaciego y cortesano, la encina niega la corte y se erige en «sombra tutelar» del agro castellano". C. Beceiro (1984), p. 51.

${ }^{22}$ A. Machado (1989), CIII, vv. 7-10, p. 500. Vila-Belda releva una analogía entre esta estrofa y una del poema XLVIII, dedicado precisamente a esas familiares "moscas vulgares" que, por no ser productivas como las laboriosas abejas o agraciadas como las delicadas mariposas, no han sido celebradas nunca por un "digno cantor": "En ambos poemas el poeta se fija en lo insignificante -moscas y encinas- para reificar, en el primer caso, la humildad y la fortaleza de la gente del campo; y en el segundo, la fugacidad del tiempo". R. Vila-Belda (2004), p. 142. 
tiene palabras de admiración por esa encina que lucha diariamente contra las adversidades y que sigue obedeciendo -"casta y buena"- a la implacable ley de la vida, frente a la que resiste "robusta y serena", no obstante todas las privaciones, las calamidades naturales y las destrucciones humanas. ${ }^{23}$

La encina, que constituye un hápax en el corpus botánico montaliano, forma parte, junto al laurel y al sauce, de esos "árboles humanísticos" que no dejan indiferente a su autor, tal y como confiesa en "Seconda maniera di Marmeladov" (recogido en el volumen de cuentos fantásticos Farfalla di Dinard), donde expresa también su predilección por una naturaleza "incolta e negletta" ${ }^{24}$ (inculta y descuidada), sin huellas del trabajo humano.

Ya se ha sugerido que Montale escoge, como estandarte de su batalla lírica, una planta simple y común como el limonero que, con el fulgor de sus agrios, desdora y oscurece los versos suntuosos y artificiosos de los escritores neoclásicos; la agridulce fragancia de sus frutos dorados, que penden de las "ramas amigas", ofrecen también a los pobres su parte de riqueza:

\author{
Aquí las diversas pasiones \\ de la guerra por milagro callan, \\ aquí también a nosotros pobres nos toca nuestra parte \\ de riqueza \\ y es el olor de los limones. ${ }^{25}$
}

${ }^{23}$ En una visión geográfica de amplio alcance, que comprende casi todas las regiones de la península ibérica, los encinares machadianos se extienden desde Aragón hasta Navarra, en las fronteras con Francia, desde Extremadura, que limita con Portugal, hasta esa Castilla que, al escribir su Historia, "hizo a España". Las pardas encinas crecen a toda altitud, tanto a nivel del mar como en cerros y montañas, y hasta en las cuencas fluviales, desde el altiplano rodeado por el río Duero, que nace en el territorio soriano, hasta el Tajo, que atraviesa el suelo toledano. Abrazan la península a todas las latitudes, del extremo Norte de la cantábrica Santander, que se asoma al mar del Golfo de Vizcaya, al extremo Sur de "Córdoba la morisca", en el corazón árabe de Andalucía, hasta ese Madrid que, situado a los pies de la fría Sierra de Guadarrama, ha transmitido a los encinares el orgullo de su "castellano ceño". Cf. A. Machado (1989), CIII, vv. 1-128, pp. 500-503.

${ }^{24}$ E. Montale (1994), p. 163. La "quercia" se incluye en la tríade de los «alberi umanistici» que Montale puede tolerar excepcionalmente porque pertenecen al paisaje familiar de su infancia, como sugiere Luca Notari: "La ragione dell'esclusione di questa triade dal gruppo di piante non amate è probabilmente legata al fatto che si tratta di vegetazioni che hanno realmente fatto parte del paesaggio montaliano originario: sarebbero cioè parte degli "alberi sacri alla [sua] infanzia", oltre che del repertorio "umanistico". M. Pozzi y L. Notari (1997), p. 291.

${ }^{25}$ E. Montale (1973), vv. 18-22, p. 19. 
En medio de un paisaje nada estilizado o idealizado pueden encontrar felicidad y sosiego también los poetas sin gloria literaria ni privilegios sociales, que aparecen identificados -según el modelo crepuscular- con la condición común de la masa.

En la última estrofa, la imagen visual del esplendor solar de los limoneros -asociada sinestésicamente a la sensación auditiva de las trompetas que preanuncian el gozo de la eufórica contemplación de los árboles familiares- ofrece al lector extasiado uno de los más sugestivos momentos de plenitud sensorial de Ossi di seppia. El limonero de la infancia se le aparece ex abrupto al joven Eugenio, en medio del tedio invernal cuando la luz se vuelve avara y el alma amarga, como el don generoso de una naturaleza madre, que ofrece a sus hijos las preciosas joyas doradas de esos limones que el sujeto lírico entrevé a través de un portal entreabierto.

Mediante una sugestiva mirada retrospectiva, también los recuerdos más remotos en el tiempo del Machado adulto, que parecen fundirse y confundirse con el ciclo vital de la naturaleza, se remontan a aquel niño que juega en el luminoso patio del Palacio de las Dueñas. Quedará esculpido en el mármol eterno de la poesía aquel lozano limonero que, madurando en el jardín de la casa sevillana, irradia su luz encantada en el espacio sagrado de la niñez: "Mi infancia son recuerdos de un patio de Sevilla / y un huerto claro donde madura el limonero" 26 .

No uno cualquiera, sino precisamente el limonero de su tierra que, sin necesitar de epítetos o determinaciones específicas, encarnará la inocencia y la despreocupación de la niñez, aquellos deseos y esperanzas que -aún no cubiertos por el polvo del tiempo- pueden refulgir del amarillo dorado de sus frutos: Joaquín Verdú de Gregorio observa que "en los primeros versos parece sugerirse que únicamente fructifica la infancia; es en ella, en su huerto, donde el limonero dará sus frutos"27.

Ya en el primer dístico de "Retrato", poema clave de la obra machadiana, se puede apreciar el binomio inseparable formado por el árbol y el huerto, pareja que se repite también en muchos de los versos montalianos, donde a veces la imagen del huerto o del jardín aparece representada metonímicamente por el "muro": se ha averiguado en los versos del poema anteriormente mencionado, en el cual el genovés, a la vez que nos proporciona la clave de lectura de su poética, esboza el paisaje de su Liguria natal.

En la composición que, en 1903, fue publicada en la revista Helios bajo el título "El poeta visita el patio de la casa en que nació", el joven Antonio retrocede a través del tiempo y del espacio, en un viaje que es mental y real al mismo tiempo, ya que los versos fueron inspirados con ocasión de un breve viaje a Sevilla con su hermano Manuel; en una tibia tarde de principio de primavera, se asoma al patio de

${ }^{26}$ A. Machado (1989), XCVII, vv. 1-2, p. 491.

${ }^{27}$ J. Verdú de Gregorio (1990), p. 98. 
su casa andaluza en busca de aquella ilusión "cándida y vieja", que parece ahora revivir en el misterioso soñar de los frutos encantados del limonero de su infancia:

El limonero lánguido suspende

una pálida rama polvorienta

sobre el encanto de la fuente limpia,

y allá en el fondo sueñan

los frutos de oro... ${ }^{28}$

Su mirada se detiene a contemplar extasiada -en un melancólico sueño con los ojos abiertos- aquella rama que el tiempo ha inclinado y cubierto de polvo, y que queda suspendida delante de nuestros ojos tal como la visión que el poeta ha recreado sentimentalmente; la languidez del árbol no es sino la sensación de dejadez y melancolía de aquel adulto que, mientras vaga por el hortus conclusus de su infancia, descubre de repente -en el fondo de sí mismo- su ilusión de niño en aquellos frutos de oro que parecen soñar con su mismo sueño:

Que tú me viste hundir mis manos puras

en el agua serena,

para alcanzar los frutos encantados

que hoy en el fondo de la fuente sueñan... ${ }^{29}$

El poeta adulto guarda en su alma las esperanzas a las que nunca ha podido renunciar y vuelve a ser otra vez aquel niño que, cautivado por su centelleo dorado, sumergía las manos en el agua de la fuente para coger los limones que se encontraban en el fondo, o quizás tan solo su reflejo. Parece casi a punto de alcanzarlos cuando, de repente, siente desvanecer su delicada fragancia, llevada por el viento de los recuerdos como una pompa de jabón.

Es la misma brisa que, en un atardecer, lleva al joven Eugenio el agrio aroma de los limones, esa penetrante fragancia que embriaga su corazón y aturde su mente, y en la que intenta indagar, unir sintéticamente o dividir analíticamente, los indescifrables secretos de la Naturaleza:

La mirada escrudiña alrededor, la mente indaga acuerda desune en el perfume que inunda cuando más languidece el día.

Son los silencios en los que se ve

${ }^{28}$ A. Machado (1989), VII, vv. 1-5, p. 432.
${ }^{29}$ Ibíd., VII, vv. 27-30, p. 433. 
en cada sombra humana que se aleja

alguna turbada Divinidad. ${ }^{30}$

El jardín de limoneros -con su claror iniciático y ancestral- representa, para ambos poetas, la patria paradisíaca y la patria eterna: el lugar de donde vienen y adonde van. Es lo que todos soñamos y para lo que vivimos, reflejo de aquel paraíso original que es, en ellos y en cada hombre, antes expulsión, luego exilio y siempre recóndita nostalgia.

Machado acoge a sus lectores en el íntimo mundo de sus sentimientos más ocultos, creando en ellos la ilusión -fugaz e impalpable- de encontrarse, por un breve instante, en aquellos luminosos "fanales" de la memoria y/o del sueño que inmortalizan en una imagen espacial el instante de una intuición vivida; y ellos se dejan guiar a lo largo de las "galerías" de su alma señera y melancólica, a través de los laberintos de sus "soledades", de sus nostalgias, de sus dudas, de sus amores no correspondidos.

Con análogas pinceladas, Eugenio Montale se detiene en la descripción de escenarios naturales que son reflejos de paisajes interiores, según aquella ósmosis hombre/naturaleza que se encarna en sus tópicos paysages de l' âme neosimbolistas. De hecho, el autor de Le Occasioni tuvo su primer contacto con la obra machadiana gracias a la imprescindible Antología de Gerardo Diego, uno de cuyos ejemplares (en su edición de 1932) dejó prestado a quien llegará a ser uno de los mayores exegetas del sevillano: el filólogo salentino Oreste Macrì, que -con los dos seminarios impartidos en la Universidad de Florencia (1971) y luego recogidos en el ensayo "Formalismo e critica letteraria (con un esercizio su Montale)"31 - es el pionero en revelar las conexiones intertextuales entre ambos y en abrir una estimulante vía comparatista que no ha sido suficientemente explorada.

El sevillano, que encierra en su esencia el alma andaluza de la infancia idealizada y la castellana del amor y del dolor de la madurez, menciona los ejemplares botánicos peculiares de ambas regiones, cuya función (tanto denotativa como connotativa) merece destacarse para tratar de demostrar que nunca se llegará a una completa y cumplida desubjetivación, puesto que la contemplación del escenario natural queda siempre trascendida por el paisaje del alma del sujeto lírico. Pasando de la geografía inconcreta de Soledades a la dibujada con pincel realista y precisos topónimos de Campos de Castilla, Machado nunca abandonará la clave simbolista en la que, en uno de los aforismos de sus Proverbios y cantares, sugería leer sus versos:

${ }^{30}$ E. Montale (1973), vv. 31-37, p. 20.

${ }^{31}$ El texto está incluido en La vita della parola: studi montaliani, Firenze, Le Lettere, 1996. 
Da doble luz a tu verso, para leído de frente y al sesgo. ${ }^{32}$

Fiel a su intento de descifrar ese misterioso "alfabeto de la lengua poética" que es el macrocosmos de la naturaleza, Machado se detiene a describir el paisaje, que representa "la mina de donde el artista ha extraído sus símbolos"33 "como si se tratara de un novelista de la generación galdosiana" "34. Sin embargo, cada ejemplar botánico, aunque aparezca integrado en su hábitat natural tópico y sea pintado "de frente" con la máxima fidelidad y precisión, desvela siempre "al sesgo" ecos emocionales y resonancias biográficas: por ejemplo, la encina y el olivo simbolizan, respectivamente, las regiones emblemáticas de su recorrido existencial, Castilla y Andalucía, la tierra natal y la "tierra de alma" ${ }^{35}$ adoptiva; el "olmo seco" es alegoría del marido devoto que, mientras siente su alma traspasada por el "rayo" que parte en dos el tronco del "olmo viejo", abraza el cuerpo frágil de Leonor para protegerlo de la agonía, sin renunciar nunca a la vana esperanza de que su mujer pueda florecer, junto a la primavera, "hacia la luz y hacia la vida"36.

Desde esta perspectiva, se desvela un Machado bifronte (en su vertiente tanto de naturalista como de escritor), lo que ofrece la oportunidad de examinar el alternarse/superponerse o desdibujarse/(re)aparecer de una u otra faceta a lo largo de sus distintos poemarios. Al recorrer los melancólicos senderos de la memoria en Soledades, el poeta intimista es como un jardinero que entra en el encantado mundo de parques y jardines, donde reconoce el perfume de las flores familiares (los geranios de áspera fragancia, la cándida sensualidad de los jazmines, la ilusión fugitiva de violetas, margaritas y velloritas primaverales, el desengaño de amor de dalias y nardos) y las "imágenes amigas" ${ }^{\text {"37 }}$ de los árboles y arbustos tópicos del simbolismo modernista (el noble laurel, el mirto de Venus, el oloroso eucalipto, los verdes evónimos, los almendros y los zarzales floridos); estas plantas, que evocan las ilusiones de la "blanca juventud nunca vivida" 38 , acogen bajo su sombra a un alma viandante que huye del presente, y recrean con emoción los escenarios pasados, generadores de sueños y, al mismo tiempo, símbolo de su inexorable fin.

Cabe destacar, además, el viraje que acusa la poética machadiana con la publicación de Campos de Castilla (1912): un poemario que, frente a las dos

\footnotetext{
${ }^{32}$ A. Machado (1989), CLXI (LXXI), vv. 1-3, p. 640.

${ }^{33}$ J. M. Aguirre (1973), p. 165.

${ }^{34}$ C. Beceiro (1984), p. 20.

${ }^{35}$ Cf. A. Machado (1989), CXVI, v. 39, p. 543.

${ }^{36}$ Cf. Ibíd., CXV, vv. 1-30, pp. 541-542.

${ }^{37}$ Ibíd., XXII, v. 9, p. 444.

${ }^{38}$ Ibíd., I, v. 19, p. 427.
} 
precedentes colecciones de Soledades (1903) y Soledades, galerías y otros poemas (1907), se puede definir como un verdadero himno a aquella "hermosa tierra de España" ${ }^{39}$ que es sinécdoque del país entero. Sumergido en el realismo temporal de los campos sorianos y determinado a alejarse del callejón sin salida a que le condujo el solipsismo nihilista de su libro anterior, ahora el andaluz dirigirá su mirada hacia la naturaleza castellana, que pintará en todo su vigor y realismo, en su orgullo rústico y austero. En las tierras altas de la meseta, emblema de su nueva conciencia y de su nueva responsabilidad, Machado renunciará definitivamente al preciosismo de la estética modernista y se orientará a la búsqueda de la genuinidad lírica, de esa dignidad que puede proceder solo de una humildad auténtica y de una consciente aceptación de la ley de la vida: es exactamente lo que hace, con modestia y resignación, el árbol más representativo del campo castellano, la encina, que en silencio lleva a cabo su trabajo diario que es "vivir como se puede"

En Campos de Castilla, Machado no se limita a "fotografiar" la naturaleza soriana en todo su desnudo verismo, sino que critica con rigor la realidad castellana y por extensión española- desde su adhesión ético-política a los ideales liberalreformistas del institucionismo: gracias a su cordial participación de la sensibilidad ética noventayochista, el poeta desvela las connotaciones heroicas de un paisaje que se yergue como viva metáfora de las glorias de un pasado ya en decadencia. El áspero paisaje castellano, símbolo de nobles valores morales, actitudes sobrias y de viril renuncia, parece responder perfectamente a la búsqueda de esa verdad desnuda, y nada idílica, que inspira a toda su generación, encarnada en el sentimiento trágico de la vida cantado por el coro de las voces noventayochistas.

De un modo análogo, los versos montalianos -nunca asépticamente descriptivos sino ambiguamente evocativos- se convierten en interpretaciones individuales y sentimentales de la naturaleza, speculum donde se reflejan las vivencias personales (cada rasgo de la esfera psicológica, emocional y cognitiva humana encuentra su correlato natural) para luego transfigurarlas según una perspectiva que adquiere un valor universal. El autor de La bufera e altro moja la pluma en el microcosmos de sus dolorosas experiencias biográficas e históricas, en sus miedos e inquietudes (los "universales del sentimiento" machadianos) que, proyectados en los elementos del entorno natural, le permiten abarcar los temas tópicos de la vida y de la muerte, del dolor humano, del misterio de la existencia, del incesante fluir del tiempo, y universalizarlos.

Para concluir, cabe señalar que el aspecto más novedoso de la investigación presentada reside en demostrar que Montale conocía bien los poemas machadianos, cuya lectura influyó y orientó la selección botánica del hermético ligur. Son muchas

${ }^{39}$ Ibíd., IX, v. 20, p. 435.
${ }^{40}$ Ibíd., CIII, v. 77, p. 502. 
las afinidades entre el Machado de los detalles ínfimos de la vegetación soriana y el Montale de Huesos de sepia, quien -vencido por el cansancio y la soledad, angustiado por una sensación de desconfianza y desconcierto y amargado ante la toma de conciencia del vacío existencial- sustituye el paisaje sublime y estilizado de la tradición dannunziana por el escenario concreto y humilde de los campos de Liguria, con la única variante básica -frente a Campos de Castilla- de que éste aparece bañado por un mar que se erige en símbolo generador de los poemas de la primera edición.

Se trata de un paralelismo sugerido por el ensayo "Durrell e Machado" (1959), escrito con ocasión de la primera publicación en Italia de las Poesie del sevillano, y en el que Montale alaba al maestro español precisamente por la peculiar manera de pintar el paisaje: "Poeta geórgico, solemne frente al misterio de la vida y la muerte, artista de una monumentalidad que recuerda a Wordsworth antes que a Pascoli, Antonio ha cantado la tierra castellana con un sentido de total, religiosa devoción" ${ }^{41}$.

\section{OBRAS CITADAS}

AGUIRRE, José María: Antonio Machado, poeta simbolista, Madrid, Taurus, 1973. ALBERTI, Rafael: "Imagen primera y sucesiva de Antonio Machado", en Imagen primera de..., ed. de Rafael Alberti, Buenos Aires, Losada, 1945, pp. 39-59. ALONSO, Dámaso: "Fanales de Antonio Machado", en Cuatro poetas españoles, Madrid, Gredos, 1962, pp. 137-184.

AZORÍN: "El paisaje en la poesía", en Clásicos y Modernos, Buenos Aires, Losada, 1959, pp. 78-79.

BARBAGALlo, Antonio: España, el paisaje, el tiempo y otros poemas, en la poesía de Antonio Machado, Soria, Diputación Provincial, 1990.

BECEIRO, Carlos: Antonio Machado, poeta de Castilla, Valladolid, Ámbito, 1984.

GINER DE LOS RíOS, Francisco: "Paisaje", La Lectura, XV, 1 (1915), pp. 361-370.

LA VALVA, Rosa Maria: The eternal child: the poetry \& poetics of Giovanni Pascoli, Chapel Hill, The University of North Carolina, 1999.

LÓPEZ CORTEZO, Carlos: Semántica de "Ossi di seppia" de E. Montale, Madrid, Universidad Complutense, 1982.

MACHADO, Antonio: Obras. Poesía y prosa, ed. de Aurora de Albornoz y Guillermo de Torre, Buenos Aires, Losada, 1973.

${ }^{41}$ La traducción es nuestra: "Poeta georgico, solenne di fronte al mistero della vita e della morte, artista di una monumentalità che fa pensare a Wordsworth piuttosto che a Pascoli, Antonio ha cantato la terra castigliana con un senso di totale, religiosa dedizione". E. Montale (1996), p. 2213. 
MACHADO, Antonio: Poesías completas, ed. de Oreste Macrì y Gaetano Chiappini, vol. II, Madrid, Espasa-Calpe / Fundación Antonio Machado, 1989.

MACRÌ, Oreste: La vita della parola: studi montaliani, Firenze, Le Lettere, 1996.

MONTALE, Eugenio: Huesos de Sepia, ed. de Francisco Ferrer Lerín: prólogo y traducción, Madrid, Alberto Corazón, 1973.

MONTALE, Eugenio: Sulla poesia, Milano, Mondadori, 1976.

MONTALE, Eugenio: Farfalla di Dinard, Milano, Leonardo, 1994.

MONTALE, Eugenio: "La fortuna di Pascoli", en Il secondo mestiere. (Prose 19201979), ed. de Giorgio Zampa, Milano, Mondadori, 1996, pp. 1889-1904.

MONTALE, Eugenio: "Durell e Machado", en Il secondo mestiere. (Prose 19201979), ed. de Giorgio Zampa, Milano, Mondadori, 1996, pp. 2209-2214.

MOSTAZA, Bartolomé: "El paisaje en la poesía de Antonio Machado", Cuadernos Hispanoamericanos, 11-12 (1949), pp. 623-641.

OROZCO DÍAZ, Emilio: Paisaje y sentimiento en la poesía española, Málaga, Universidad de Málaga, 2010.

POZZI, Marcella y NOTARI, Luca: Fiori e piante nella poesia di Pascoli e di Montale, Friburgo, Edizioni Universitarie Friburgo Svizzera, 1997.

VERDÚ DE GREGORIO, Joaquín: Antonio Machado: Soledad, infancia y sueño, Madrid, Fondo de Cultura Económica, 1990.

VILA-BELDA, Reyes: Antonio Machado, poeta de lo nimio: alteración de la perspectiva, Madrid, Visor Libros, 2004.

ZUBIRÍA, Ramón de: La poesía de Antonio Machado, Madrid, Gredos, 1973. 